\title{
Long term high intensity exercise and damage of small joints in rheumatoid arthritis
}

\section{Z de Jong, M Munneke, A H Zwinderman, H M Kroon, K H Ronday, W F Lems, B A C Dijkmans, F C Breedveld, T P M Vliet Vlieland, J M W Hazes, T W J Huizinga}

See end of article for authors' affiliations

Correspondence to: Mrs Z de Jong,

Albinusdreef 2 Leiden, 2300 RC, The

Netherlands; z.de_jong@ lumc.nl

Accepted

21 December 2003
Objective: To investigate the effect of long term high intensity weightbearing exercises on radiological damage of the joints of the hands and feet in patients with rheumatoid arthritis (RA).

Methods: Data of the 281 completers of a 2 year randomised controlled trial comparing the effects of usual care physical therapy (UC) with high intensity weightbearing exercises were analysed for the rate of radiological joint damage (Larsen score) of the hands and feet. Potential determinants of outcome were defined: disease activity, use of drugs, change in physical capacity and in bone mineral density, and attendance rate at exercise sessions.

Results: After 2 years, the 136 participants in high intensity weightbearing exercises developed significantly less radiological damage than the 145 participants in UC. The mean (SD) increase in damage was 3.5 (7.9) in the exercise group and $5.7(10.2)$ in the UC group, $p=0.045$. Separate analysis of the damage to the hands and feet suggests that this difference in rate of increase of damage is more pronounced in the joints of the feet than in the hands. The rate of damage was independently associated with less disease activity, less frequent use of glucocorticoids, and with an improvement in aerobic fitness. Conclusion: The progression of radiological joint damage of the hands and feet in patients with RA is not increased by long term high intensity weightbearing exercises. These exercises may have a protective effect on the joints of the feet.
$\mathrm{R}$ heumatoid arthritis (RA) is a disease characterised by local bone destruction and accompanied by systemic bone loss. Locally, synovial inflammation results in periarticular osteoporosis and subsequent development of bone erosions, with the joints of the hands and feet most commonly affected. At a systemic level, bone loss manifests itself in osteoporosis. This bone loss is assumed to be the result of several factors such as disease activity, use of glucocorticoids, and a decrease in physical capacity. ${ }^{1-5}$ In recent cross sectional studies, an association between local and systemic bone loss was found, ${ }^{67}$ and more bone erosions were associated with a lower bone mineral density (BMD). It has been suggested that local and systemic bone loss are interrelated, with the osteoclast being the common effector cell. In active synovitis, increased production of proinflammatory cytokines is presumed to be responsible for the activation of osteoclasts locally and systemically, and consequent bone loss. ${ }^{8-10}$

Recently, a long term high intensity weightbearing exercise programme was shown to be effective in increasing the physical capacity, functional ability, and emotional status of patients with RA when compared with usual care physical therapy (UC). ${ }^{11}$ In that randomised controlled trial, the effects of the exercises on bone loss were also examined. No additional damage to the large weightbearing joints was found, with the exception of a small group of patients who had significant baseline damage in these joints. This limited additional damage was attributed to excessive wearing. Exercise was found to prevent systemic bone loss. ${ }^{12}$ The decline in BMD of the hip was postponed in the exercise group in comparison with the UC group. This effect was attributed to the long term high intensity weightbearing exercises, effective in increasing aerobic fitness and muscle strength.

At this moment, little is known about the effects of exercise on radiological joint damage of the hands and feet.
Four studies have reported the effects of long term intensive exercises on the radiological damage of the joints of hands and/or feet. ${ }^{13-16}$ In one study a decreased rate of radiological damage of the joints of the hands and/or feet was found in the exercise group in comparison with control. ${ }^{13}$ The remaining three studies ${ }^{14-16}$ did not show any significant difference in the rate of damage of the joints of hands and feet between the exercise and the control group. Possible reasons for this lack of consistency are the low numbers of participants in each study and differences in design, including differences in the impact loading of the skeleton.

To investigate the effect of long term high intensity weightbearing exercises on the radiological joint damage of the hands and feet we used the data of a large randomised controlled trial (the Rheumatoid Arthritis Patients In Training (RAPIT) study). ${ }^{11}{ }^{12}$ Secondly, we examined which exercise related factors predict, after adjusting for disease activity and use of glucocorticoids, the local bone destruction of the joints of hands and feet in these patients.

\section{PATIENTS AND METHODS}

\section{Study participants}

The patients under investigation are completers of the RAPIT study. The RAPIT study was originally designed to investigate the effectiveness and safety of long term high intensity weightbearing exercises. This study provided data from 2 years, from 1998 until 2000. The patients who were recruited for the RAPIT study had to fulfil the following

\footnotetext{
Abbreviations: $A C R$, American College of Rheumatology; AF, aerobic fitness; AUC, area under the curve; BMD, bone mineral density; DAS4, Disease Activity Score with four variables; DMARD, disease modifying antirheumatic drug; DXA, dual photon $x$ ray absorptiometry; $H A Q$, Health Assessment Questionnaire; ICC, intraclass correlation coefficient; $I Q R$, interquartile range; $M S$, muscle strength; $R A$, rheumatoid arthritis; RAI, Ritchie Articular Index; RAPIT, Rheumatoid Arthritis Patients In Training; SDD, smallest detectable difference; UC, usual care
} 


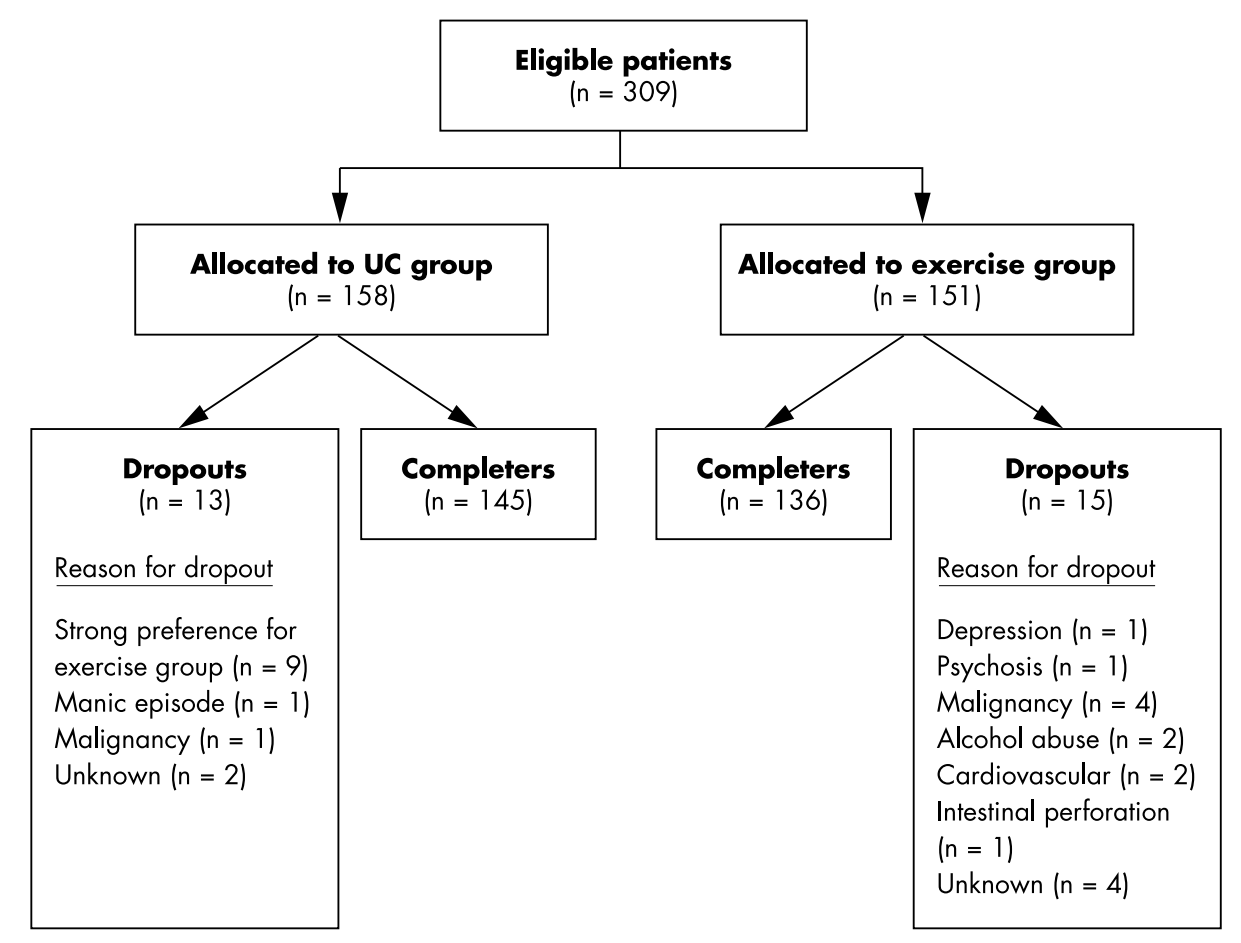

Figure 1 Recruitment procedure.

inclusion criteria: age 20-70 years, RA according to American College of Rheumatology (ACR) criteria 1987, ${ }^{17}$ ACR functional class I-III, ${ }^{18}$ stable disease modifying antirheumatic drug (DMARD) intake in past 3 months, and no prosthesis of a weightbearing joint. Those patients who met these criteria and who gave written informed consent were subsequently randomised.

The medical ethics committee of each participating centre approved the study protocol.

\section{RAPIT study protocol}

For the RAPIT study, 309 patients were randomised (fig 1). Nine randomised patients refused participation immediately after randomisation and did not cooperate in baseline measurements. Over the period of 2 years, 19 patients did not complete this trial for different reasons. ${ }^{11}$ From the 281 participants who completed the RAPIT study (completers), 136 were participants in the high intensity weightbearing exercise programme (exercise group) and 145 were participants in the control group (UC group).

The attending physicians of all participants were informed about the treatment allocation and had free choice about their medical prescriptions and other treatment strategies.

Patients assigned to the UC group were treated by a physical therapist if regarded necessary by their attending physician. It was agreed that they would not participate in any supervised or unsupervised high intensity exercise sessions during the trial period. The patients randomly allocated to the exercise group participated in a supervised intensive biweekly group exercise programme. None of the patients in either group were explicitly encouraged to participate in any free time physical activity.

Attendance at any group or individual physical therapy sessions apart from the RAPIT programme was recorded in both groups.

\section{Baseline and follow up measurements}

At baseline, sociodemographic characteristics were registered as well as disease duration, presence of rheumatoid factor
(RF), past and present use of DMARDs, and current use of oral glucocorticoids.

\section{Outcome variables}

The primary outcome variable in the present study on local bone destruction was defined as the change in radiological joint damage of the hands and feet after 2 years of study. The following potential determinants of change in radiological joint damage were included: disease activity, the use of drugs (DMARDs and glucocorticoids), change in physical capacity (aerobic fitness and muscle strength), change in BMD of the hip, and attendance rate at exercise sessions.

Radiological joint damage of the hands and feet Radiological joint damage of the hands and feet was assessed using the method devised by Larsen $e t$ a ${ }^{19}$ and modified by Scott et al. ${ }^{20}$ The following joints were assessed: the 10 proximal interphalangeal joints, the 10 metacarpophalangeal joints, the wrists (scored as one unit and multiplied by five), the fifth to the second metatarsophalangeal joints, and the first interphalangeal joints. According to this method the Larsen score of the hands and feet (Larsen score) varies from 0 (no joint space narrowing, no erosions) to 200 (maximum possible damage). The number of damaged joints was also assessed. The number of joints with a score $>0$ was counted and varies from 0 (no joint with score $>0$ ) to 32 (each joint assessed damaged).

A single observer (AC) scored the radiographs. All radiographs were scored without information on their time sequence, the patient's identity, and the treatment received. The intraclass correlation coefficient (ICC) based on repeated readings of 19 radiographs by the single observer with 4 weeks' interval between the readings was 0.96, mean difference (SD) in Larsen score 0.69 (6.7).

\section{Disease activity}

Disease activity was assessed with the original Disease Activity Score with four variables (DAS4). ${ }^{21}$ The DAS4 is a compiled index based on a 44 joint count for swelling (SW44; 
range 0-44), tender joint count (Ritchie Articular Index (RAI); range 0-78), erythrocyte sedimentation rate, and the patient's global assessment of disease activity measured on a visual analogue scale (range $0-100$ ). The DAS4 ranges from 0 (no disease activity) to 10 (severe disease activity). The changes during the 2 year study period preceding the follow up measurement of the end points were expressed as area under the curve (AUC DAS4).

\section{Drug use}

Drug use (oral glucocorticoids and DMARDs) was reported by the patients at each 3 monthly visit. The use of glucocorticoids is presented after conversion into the number of months from the start of the study during which the patients reported the use. The number of months of use can thus vary from 0 (never used) to 24 (used every month of the study). The cumulative dose of prednisolone was also calculated. Any changes in the use of DMARDs were interpreted by a rheumatologist $(\mathrm{ZdJ})$ as changes in RA activity: $0=$ decreased disease activity; $1=$ no change in disease activity; 2 = increased disease activity. Changes in the use of DMARDs after 2 years can thus vary from 0 (decrease in disease activity at every visit) to 16 (increase in disease activity at every visit).

\section{Physical capacity}

Physical capacity was determined by aerobic fitness (AF) and muscle strength (MS). AF was measured by a standardised ergometer test and is given in watts (W). ${ }^{22}$ MS of the knee extensors was measured with an isokinetic dynamometer at an angle velocity of $60 \%$ and is given in newtons $(\mathrm{N})^{23}$

\section{Bone mineral density}

BMD measurements of the hip in the total hip region were carried out by dual photon $x$ ray absorptiometry (DXA) and are given in $\mathrm{g} / \mathrm{cm}^{2}$. Hologic QDR-2000 was used in one centre (Amsterdam), QDR-4500 in two other centres (Leiden, The Hague). The scanning and standard quality procedures were followed. All measurements of one patient were performed using the same DXA. The in vitro reproducibility expressed as coefficient of variation was $3.7 \%$ and $2.6 \%$ for the Hologic QDR-2000 and Hologic QDR-4500, respectively.

\section{Attendance rate}

Attendance rate was recorded for each individual participant in the exercise group and is expressed as a percentage of the maximum possibly attended exercise sessions. For the attendance rate of participants in the UC group, 0 was substituted.

\section{Assessments}

The assessments were done at baseline and at 6, 12, 18, and 24 months. Moreover, every 3 months the participants reported on their drug use, and disease activity and physical capacity were assessed. Bone mineral density and radiological joint damage were assessed only at baseline and after 12 and 24 months.

All clinical outcome assessments were done by four research physical therapists who were trained thoroughly before the trial and after 1 year. A manual of procedures and assessment techniques was available in each centre. A reproducibility study in 19 patients showed ICCs for AF, MS, SW44, and RAI of 0.97, 0.98, 0.83, and 0.92, respectively.

\section{Statistical analysis}

Because the RAPIT study was primarily designed with the Health Assessment Questionnaire (HAQ) as a primary outcome variable, the target sample size was calculated to detect a difference of 0.20 in the change of the HAQ. ${ }^{11}$ This difference is assumed to be clinically relevant. ${ }^{24}$ Based on 0.9 power to detect a significant difference $(p=0.05$, two sided $)$ and assuming a standard deviation of $0.5,119$ patients would be required for each study group. To compensate for an expected dropout rate of about $20 \%$ we planned to enrol at least 150 patients in each study group. Final analyses are based on an intention to treat as initially assigned on the data of the 281 completers of the study.

We used the smallest detectable difference (SDD) of the change score calculated according to Lassere et $a^{25}$ as a threshold for relevant progression in radiological damage of the joints of hands and feet and as a surrogate for clinically relevant increase in damage

At all times, measures with a Gaussian distribution are expressed as a mean (SD) and measures with a non-Gaussian distribution as median and interquartile range (IQR). At baseline, differences between the groups were analysed with the Mann-Whitney U test or $\chi^{2}$ test, where appropriate.

To analyse the effects of the long term high intensity weightbearing exercise programme on the radiological joint damage of the hands and feet after 1 and 2 years the changes from baseline (follow up minus baseline measurement) were compared by analysis of variance. They are presented as a mean difference in change between the groups $195 \%$ confidence interval (95\% CI)) after correction for the baseline differences. To compare the effects over the total period of 2 years, repeated measures were analysed with mixed effects analysis of variance models, with patient number as random factor, and treatment, time, and the treatment by time interaction as fixed effects. Values of $p \leqslant 0.05$ are considered statistically significant.

Multivariate analyses were used to explore the relationships between the dependent variable change in radiological joint damage and the independent variables-disease activity, use of DMARDs and glucocorticoids, change in physical capacity and in BMD, and attendance rate at the exercise sessions. These analyses were performed as a multiple linear regression model. Based on the supposed clinical relevance and the results of the multivariate analysis, variables were successively removed from the multiple regression models in a backward fashion. The risk for development of radiological damage is expressed as unstandardised regression coefficient (B), SE, and a level of significance ( $\mathrm{p}$ value). All analyses were performed using SPSS program, version 10.0.

\section{RESULTS}

Table 1 shows the baseline characteristics of all 281 completers of the RAPIT study.

At baseline, the participants of the UC group and the exercise group had similar characteristics, except for a slightly longer duration of RA and more radiological joint damage of the hands and feet in the UC group (Larsen score hands and feet). When the radiological damage of the hands and feet was analysed separately, the treatment groups appeared to differ significantly only in damage of the hands $(\mathrm{p}=0.043)$ but not of the feet $(\mathrm{p}=0.085)$ (table 2$)$. The mean changes in variables are, therefore, where appropriate, presented after correction for baseline differences.

\section{Participation in exercises}

In the course of the 2 years, $80(55 \%)$ and $46(34 \%)$ of the participants in the UC and the exercise group, respectively, were treated individually by a physical therapist at least once. The physical therapy involved hydrotherapy and different types of physical therapy (passive, active, or applications). None of the patients participated in any high intensity weightbearing exercises except in the programme under study. 
Table 1 Baseline demographic and disease related characteristics of 281 RAPIT study completers

\begin{tabular}{|c|c|c|c|}
\hline & $\begin{array}{l}\text { All completers } \\
\text { ( } \mathrm{n}=281)\end{array}$ & $\begin{array}{l}\text { Exercise group } \\
(n=136)\end{array}$ & $\begin{array}{l}\text { UC group } \\
(n=145)\end{array}$ \\
\hline \multicolumn{4}{|l|}{ Demographic characteristics } \\
\hline Age (years) & $54(16)$ & $54(16)$ & $54(16)$ \\
\hline Body mass index $\left(\mathrm{kg} / \mathrm{m}^{2}\right)$ & $26(6)$ & $26(5)$ & $26(6)$ \\
\hline Female, № (\%) & $225(80)$ & $110(81)$ & 115 (79) \\
\hline Postmenopausal women, No (\% of the women) & $138(61)$ & $63(57)$ & $75(65)$ \\
\hline \multicolumn{4}{|l|}{ Disease related characteristics } \\
\hline Duration of RA (years) & $6(9)$ & $5(7)$ & $7(11)^{*}$ \\
\hline Rheumatoid factor positive, No (\%) & $197(70)$ & $96(71)$ & $101(70)$ \\
\hline DMARDs used in the past $(\mathrm{n})$ & $2(1-2)$ & $1(1-2)$ & $2(1-2)$ \\
\hline Current use of DMARDs, No (\%) & $241(86)$ & $111(82)$ & $130(90)$ \\
\hline Current use of glucocorticoids, No (\%) & $25(8.9)$ & $11(8.1)$ & $14(9.7)$ \\
\hline $\mathrm{ESR}(\mathrm{mm} / 1 \mathrm{st})$ & $16(21)$ & $16(21)$ & $16(22)$ \\
\hline 44 Joint count for swelling $(0-44)$ & $12(12)$ & $12(12)$ & $11(12)$ \\
\hline Ritchie Articular Index (0-78) & $8.0(10.0)$ & $8(10.0)$ & $9(11.0)$ \\
\hline $\begin{array}{l}\text { Patient's global assessment of disease activity } \\
(0-100)\end{array}$ & $3.2(4.1)$ & $3.0(4.0)$ & $3.3(4.3)$ \\
\hline DAS4 $(0-10)$ & $3.3(0.7)$ & $3.2(1.4)$ & $3.4(2.0)$ \\
\hline $\mathrm{HAQ}(0-3)$ & $0.63(0.75)$ & $0.63(0.88)$ & $0.63(0.84)$ \\
\hline Aerobic fitness (W) & $162(74)$ & $162(74)$ & $162(74)$ \\
\hline Larsen score $(0-200)$ & $31.0(58.0)$ & $24.0(54.5)$ & $37.5(54.5)^{\star}$ \\
\hline Bone mineral density $\left(\mathrm{g} / \mathrm{cm}^{2}\right)$ & $0.909(0.194)$ & $0.912(0.210)$ & $0.906(0.187)$ \\
\hline \multicolumn{4}{|c|}{$\begin{array}{l}\text { Except when indicated otherwise, values are median (IQR). } \\
\text { IQR, interquartile range expressed as a net result of the } 75 \text { th centile- } 25 \text { th centile; RAPIT, Rheumatoid Arthriti } \\
\text { Patients In Training; UC, usual care; DMARDs, disease modifying antirheumatic drugs; DAS4, disease activity } \\
\text { score with four variables; HAQ, Health Assessment Questionnaire. } \\
{ }^{*} \mathrm{p}<0.05 \text { by Mann-Whitney U test or } \chi^{2} \text { test, where appropriate. }\end{array}$} \\
\hline
\end{tabular}

\section{Use of DMARDs and glucocorticoids}

At baseline, $26(19 \%)$ of the exercise and $15(10 \%)$ of the UC group completers were using no DMARD $(\mathrm{p}=0.061) ; 97$ $(71 \%)$ of the exercise group $v 115(79 \%)$ of the UC group completers were using monotherapy $(p=1.000)$; and 13 $(9.6 \%) \vee 15(10.3 \%)$ combination therapy $(\mathrm{p}=0.845)$. After 2 years, $31(23 \%)$ of the exercise $v 34(23 \%)$ UC group participants were using no DMARD $(\mathrm{p}=0.886) ; 82(60 \%) v$ 97 (67\%) were using monotherapy; and 23 (17\%) v 14 (10\%) combination therapy. None of the patients were treated with a tumour necrosis factor $\alpha$ blocking agent. The differences between the groups in the use of DMARDs did not reach significance. In addition, no differences between the groups were found in disease activity as judged by DAS4 ${ }^{11}$ or changes in use of DMARDs during the study period,

The mean (minimum-maximum) cumulative dose of glucocorticoids was $63.8(0.0-1069.0) \mathrm{mg}$ in the exercise and $57.1(0.0-900.0) \mathrm{mg}$ prednisolone equivalents in the UC group $(\mathrm{p}=0.284)$. After 2 years, $21(15 \%)$ completers of the exercise group and $16(11 \%)$ completers of the UC group had ever used glucocorticoids $(\mathrm{p}=0.224)$.

\section{Effect of a long term high intensity exercise programme on rate of damage of the small joints}

Owing to missing radiographs of either the hands or the feet, or both, the Larsen score could be determined at baseline in

Table 2 Radiological joint damage of the hands and feet (measured by the Larsen score) of the 281 completers of the RAPIT study

\begin{tabular}{|c|c|c|c|}
\hline Radiological damage & Exercise group & UC group & $\begin{array}{l}\text { Mean difference }(95 \% \mathrm{Cl})^{*} \\
\text { Exercise-UC }\end{array}$ \\
\hline \multicolumn{4}{|l|}{ Hands and feet } \\
\hline Baseline $(n=275)$ & $34.5,24.0(54.5)$ & $43.7,37.5(54.5)$ & \\
\hline Change after 1 year $(n=268)$ & $2.0,0.0(4.0)$ & $3.1,0.016 .0$ & $-0.9(-2.6$ to 0.0 .7$)$ \\
\hline \multirow{2}{*}{ Change after 2 years $(n=272)$} & $3.6,1.0(6.0)$ & $5.7,2.0(9.0)$ & $-2.1(-4.2$ to 0.2$)$ \\
\hline & & & $p=0.045 \dagger$ \\
\hline \multicolumn{4}{|l|}{ Hands only } \\
\hline Baseline $(n=277)$ & $23.8,17.0(39.0)$ & $30.6,25.0(48.0)$ & \\
\hline Change affer 1 year $(n=272)$ & $1.5,0.0(2.3)$ & $2.1,0.0(3.0)$ & $-0.5(-1.8$ to 0.9$)$ \\
\hline Change after 2 years $(n=274)$ & $2.9,0.0(5.0)$ & $4.2,1.0(7.0)$ & $-1.2(-3.1$ to 0.7$)$ \\
\hline & & & $p=0.132 \dagger$ \\
\hline \multicolumn{4}{|l|}{ Feet only } \\
\hline Baseline $(n=276)$ & $10.8,6.0(19.0)$ & $13.1,9.0(20.0)$ & \\
\hline Change after 1 year $(n=271)$ & $0.5,0.0(1.0)$ & $0.9,0.0(2.0)$ & $-0.5(-1.1$ to 0.2$)$ \\
\hline Change after 2 years $(n=273$ ) & $0.7,0.0(1.0)$ & $1.5,0.0(3.0)$ & $-0.8(-1.6$ to -0.1$)$ \\
\hline & & & $p=0.047 \dagger$ \\
\hline
\end{tabular}

Baseline values are given as the mean, median (IRQ). IRQ, interquartile range is expressed as a net result of the 75th-25th centile.

Change values are given as mean, median (IQR) difference from baseline values.

*Mean difference $(95 \%$ confidence interval $(95 \% \mathrm{CI}))$ between change in the exercise group and change in the UC group after correction for baseline differences; $t p$ value is a result of mixed effects analysis of variance. RAPIT, Rheumatoid Arthritis Patients In Training; UC, usual care. 
Table 3 Relationship between the disease, disease treatment and exercise related factors* and the change in radiological joint damage after 2 years

\begin{tabular}{llll}
\hline & $\begin{array}{l}\text { Patients in each } \\
\text { group (n) }\end{array}$ & $\begin{array}{l}\text { Slow increase in } \\
\text { damage }\end{array}$ & $\begin{array}{l}\text { Fast increase in } \\
\text { damage }\end{array}$ \\
\hline Baseline Larsen score (0-200), median (IQR) & $166 / 106$ & $20.0(48.3)$ & $51.0(53.5) \dagger$ \\
AUC DAS4 & $166 / 106$ & $20.3(7.8)$ & $23.9(8.0) \dagger$ \\
Use of DMARDs (0-16) & $166 / 106$ & $0.3(0.4)$ & $0.4(0.4) \dagger$ \\
Use of glucocorticoids (0-24), months & $166 / 106$ & $1.9(6.0)$ & $3.2(7.2)$ \\
Change in muscle strength (N), median (IQR) & $156 / 99$ & $8.25(31.9)$ & $3.5(31)$ \\
Change in aerobic fitness (W), median (IQR) & $151 / 97$ & $0.15(46.10)$ & $-0.1(39.5) \dagger$ \\
Change in BMD (g/ $\mathrm{cm}^{2}$ ) & $162 / 104$ & $-0.015(0.043)$ & $-0.025(0.069)$ \\
Attendance rate in exercise sessions (0-100), & $166 / 106$ & $12.2(77.8)$ & $0.0(69.1)$ \\
median (IQR) & & & \\
\hline
\end{tabular}

*Except when indicated otherwise, values are mean (SD); $\uparrow p<0.05$ Mann-Whitney $U$ test fast increase in damage $\checkmark$ slow increase in damage subgroup.

Fast increase in damage is defined as a change in the Larsen score higher than the mean change for the whole group of completers (>4.67); slow increase in damage is defined as a change in Larsen score equal to or lower than the mean change $(\leqslant 4.67)$.

AUC DAS4, area under curve disease activity score four variables; DMARDs, disease modifying antirheumatic drugs; BMD, bone mineral density; IQR, interquartile range. IQR is expressed as a net result of 25 th- 75 th centile.

only 275 (142 of the UC and 133 of the exercise group) completers. Also, after 1 year the change in Larsen score could be calculated in only 268 ( 138 of the UC and 130 of the exercise group) and after 2 years in 272 (139 of the UC and 133 of the exercise group) completers.

Table 2 demonstrates that the damage of the hands and feet (Larsen score of the hands and feet) increased significantly less in the participants in the exercise group than in the UC group participants. Separate analysis of the damage of the hands and feet suggests that this difference in rate of increase in damage was more pronounced in the joints of the feet than in those of the hands.

The SDD of the progression of the Larsen score, based on the scores of the repeated measurements of the single observer, amounts to 11.5. Using the SDD as a threshold for relevant progression in damage of the small joints, we found that it was exceeded in 30/139 (22\%) UC group participants and 15/133 ( $11 \%)$ exercise group participants $(p=0.022)$.

At baseline, the median (IQR) number of joints of hands and feet damaged (defined as Larsen score $>0$ ) was 8.0 (12.4) in the UC and 6.2 (13.7) in the exercise group $(p=0.176)$. When analysed separately for the joints of hands and feet, again, no significant differences between the two groups were noted.

After 2 years the number of damaged joints increased in both groups and this was true for both hands and feet and also when analysed separately. Mean (SD) increase in the total number of damaged joints was $1.3(2.1)$ and 0.8 (1.1) in the UC and RAPIT groups $(p=0.142)$, respectively, and this increase in the number of newly damaged joints was similar in the hands and feet (data not shown).

\section{Relationship between the disease, disease treatment and exercise related factors, and the change in radiological joint damage after 2 years}

To illustrate the relationship between disease, disease treatment and exercise related factors and the change in radiological joint damage (expressed as Larsen score) after 2 years, we constructed two subgroups based on the distribution of change in radiological joint damage. Based on a mean change in Larsen score after 2 years (4.67) we constructed a subgroup with change in Larsen score $\leqslant 4.67$ (termed slow increase in damage) and a subgroup with change $>4.67$ (termed fast increase in damage).

Table 3 shows that, in comparison with patients with a slow increase in damage, the patients with a fast increase in damage were those with a significantly higher baseline Larsen score, higher disease activity during the study (as defined by AUC DAS4 and by changes in use DMARDs), and those patients who showed a decrease instead of increase in aerobic fitness. Furthermore, the patients with fast increase in damage showed a trend towards more frequent use of glucocorticoids, less improvement in muscle strength, faster loss of BMD, and a lower attendance rate at exercise sessions than patients with a slow increase in damage.

To establish which of these factors was associated with the outcome we performed univariate analyses. The following factors were explored: disease activity (defined by AUC

Table 4 Univariate and multivariate analysis* of risk factors for change in radiological damage of the small joints in 281 completers of the RAPIT study

\begin{tabular}{lccc}
\hline & $\begin{array}{l}\text { Univariate } \\
\text { column 1 }\end{array}$ & $\begin{array}{l}\text { Multivariate } \\
\text { column 2 }\end{array}$ & $\begin{array}{l}\text { Stepwise selected } \\
\text { column 3 }\end{array}$ \\
\hline Baseline Larsen score small joints & $0.05(0.01) \ddagger$ & $0.04(0.02) \ddagger$ & $0.05(0.02) \ddagger$ \\
AUC DAS4 & $0.32(0.07) \ddagger$ & $0.22(0.07) \ddagger$ & $0.21(0.07) \ddagger$ \\
Use of DMARDs & $2.67(1.43)$ & $1.14(1.43)$ & $0.16(0.08) \dagger$ \\
Use of glucocorticoids & $0.24(0.13) \ddagger$ & $0.17(0.09) \dagger$ & $-0.04(0.01) \dagger$ \\
Change in muscle strength & $-0.01(0.02)$ & $-0.03(0.02)$ & \\
Change in aerobic fitness & $-0.04(0.02)$ & $-0.01(0.02) \dagger$ & \\
Change in BMD & $-18.45(10.41)$ & $-1.59(10.20)$ & \\
Attendance rate in exercise sessions & $-0.03(0.02) \dagger$ & $-0.03(0.02)$ & \\
\hline
\end{tabular}

*Linear regression analysis; results given as unstandardised regression coefficients (B) with standard error (SE) and a level of significance ( $p)$

$\uparrow \mathrm{p}<0.05 ; \neq \mathrm{p}<0.005$.

AUC DAS4, area under the curve disease activity score four variables; DMARDs, disease modifying antirheumatic drugs; BMD, bone mineral density. 
DAS4), and changes in the use of DMARDs and of glucocorticoids (range 0-24) during the study period. Additional variables were change in muscle strength and in aerobic fitness, and the change in BMD after 2 years. To account for the possibility of exercise modalities potentially influencing the rate of bone loss-for example, by impact loading or versatile movements, and which might not be accounted for by the changes in muscle strength or aerobic fitness, attendance rate was also included in the model.

Univariate analyses show (table 4, column 1) that the following factors were significantly associated with increased rate of damage: higher baseline radiological damage (Larsen score), higher disease activity (AUC DAS4), more frequent use of glucocorticoids, and lower attendance rate at the exercise sessions. To analyse the relationship between the outcome variable and these factors simultaneously, a multivariate analysis was performed (table 4, column 2). This demonstrates that a higher rate of damage is independently predicted by higher baseline damage (unstandardised regression coefficient (standard error); 0.04 (0.02), p<0.005), higher disease activity $(0.22(0.07), \mathrm{p}<0.005)$, more frequent use of glucocorticoids $(0.17(0.09), \mathrm{p}<0.05)$, and a decrease in aerobic fitness $(-0.01(0.02), \mathrm{p}<0.05)$. In the backwardsstepwise selection of significant covariates (table 4, column $3)$, baseline damage, disease activity, use of glucocorticoids, and change in aerobic fitness remained in the model.

\section{DISCUSSION}

The data from this large randomised controlled trial (RAPIT trial) suggest that patients with RA participating in long term high intensity weightbearing exercise classes develop less radiological joint damage in the feet than patients participating in usual care physical therapy. In addition to the decrease in disease activity and in the use of glucocorticoids (disease related factors), an increase in aerobic fitness (exercise related factor) independently predicts a decrease in the rate of damage.

Previous investigations on the effects of intensive exercise on joint damage have been contradictory. In a nonrandomised controlled trial by Nordemar et al, ${ }^{13} 46$ patients with RA participating in a long term exercise programme were studied for 4-6 years. Only those joints in the lower extremities which had ever shown any arthritic features were analysed before and after the study by radiography. The authors claimed that there was more pronounced radiological progression in these joints in the non-training group than in the training group. Hansen et al examined the effectiveness and safety of four different exercise programmes in 75 patients with RA participating in a 2 year randomised controlled trial. ${ }^{14}$ No effects were noted either on aerobic fitness and/or muscle strength, or on the rate of damage of the small joints. Stenström et al investigated the effects of a long term aquatic exercise on the rate of damage of the joints of hands and feet in 60 patients with RA and also found no difference between the groups. ${ }^{15}$ Häkkinen et al included 70 patients with early RA in their well designed randomised controlled trial on the effectiveness of long term high intensity weightbearing muscle strengthening exercises. ${ }^{16}$ They observed that these exercises, effective in increasing muscle strength and physical function, did not affect the rate of damage of the small joints. This lack of consistency in reported results is probably a consequence of factors such as different trial designs, a questionable trial design, ${ }^{13}$ low number of participants, ${ }^{13-16}$ and/or either lack of weightbearing. ${ }^{15}$

This is the first time that improvement in aerobic fitness has been shown to predict, independently of other factors, a decrease in the rate of local bone damage. This finding seems to be in concordance with our earlier observation demonstrating that improvement in aerobic fitness is associated with a decreased rate of systemic bone loss. ${ }^{12}$ These observations are also in agreement with the currently accepted mechanism on the development of bone loss in patients with RA. ${ }^{26} 27$

What does aerobic fitness represent? Change in aerobic fitness was in our study brought about by diverse exercises, such as bicycling, as well as by stepping, stair walking, sport, and game activities, which also generate impact loading. It has been suggested that loading of the skeleton by weightbearing and impact delivering exercises activates bone remodelling and, if sufficiently powerful, results in a net increase in the BMD and production of bone more resistant to stress. ${ }^{26}{ }^{27}$ This hypothesis seems to be supported in our study by the finding that the decrease in erosion rate of the hand and feet joints is most pronounced in the feet joints, which were, naturally, more subject to loading than the joint of the hands.

On the cellular level, the osteoclast is presumed to be the final common cell in local and systemic bone destruction. The role of the osteoclast is supported by recent investigations on a serum transfer model of arthritis, which leads in wild-type mice to severe bone erosions. ${ }^{28}$ Evidence suggests that an essential step in the development of bone erosions is the degradation of bone matrix by osteoclasts and that the differentiation and activation of osteoclasts is mediated by the RANK-RANKL axis. ${ }^{29-32}$ Starting from these findings obtained by laboratory research and from recent cross sectional studies on patients with RA, ${ }^{67}$ we might hypothesise that local and systemic bone loss in patients with RA is also interrelated with a common effector cell, the osteoclast. If this applies, we would then expect that the change in BMD would predict the rate of bone erosion-radiological joint damage. In our study group we were not able to demonstrate such a relationship. However, the exercises increased the BMD as shown by DXA of the hip, which is a measure of change in radiographic bone density but does not provide information on quality, strength, and resistance of bone and cartilage towards mechanical and inflammatory stress.

From a clinical-epidemiological point of view, bias in our study is possible. The target sample size of the RAPIT study was based on the ability to detect a clinically relevant change in the HAQ score and not on the ability to assess the effect on joint erosions, nor to determine the risk factors for progression of erosions. We estimated that, with the sample size of about 150 patients in each treatment group and the observed standard deviation of the change of the Larsen score after 2 years of 9.2, the detectable difference between (treatment) groups is about $3(80 \%$ power). However, despite the fact that the study was underpowered to find a clinically relevant difference, we found a small but statistically significant (but possibly not clinically relevant) difference between the groups. This finding provides clinical support for the current view of an association between the increase of bone density by exercise and the progression of joint damage.

The randomisation procedure created two groups, which differed in their disease duration and radiological baseline damage of the small joints (Larsen score). The eventual UC group completers are patients with a longer RA duration and as a consequence, more radiological joint damage than the completers of the exercise group. These differences were probably caused by withdrawal of nine patients (eight from the UC group and one from the exercise group) directly after the randomisation (fig 1). It can be argued that the differences in joint damage progression found in our study are due to these post-randomisation effects, which created groups with a different disease course.

There are several arguments against such bias. Firstly, recent publications show that the rate of damage progression is independent of the RA duration. ${ }^{33}$ Secondly, it should be 
noted that disease activity or use of DMARDs and glucocorticoids did not differ between the exercise and the UC group at any time. Finally, separate analysis of the hand and feet joints demonstrated that at baseline the inequality in damage between the groups was present for the largest part in the hands, whereas it was the feet joints which seem to profit most from exercising.

Nevertheless, we have corrected for the differences at baseline wherever present and demonstrate that the mean differences in change between the groups after correction for these differences were, indeed, in favour of the exercise group.

The evidence on radiological damage of the small joints is based on readings of the radiographs by a single observer. It might be argued that reported data suggest that more than one observer should be used to minimise the bias. ${ }^{34}$ However, the mean difference (SD) of test-retest of the single observer $(0.69(6.7))$, the intraobserver intraclass correlation coefficient (0.96), and the SDD based on the progression score (11.5) were satisfactory given the size of the study.

In conclusion, we provide evidence that participation in a long term high intensity weightbearing exercise programme comprising improvement in aerobic fitness and impact generating activities does not increase the rate of radiological joint damage of the hands and feet in patients with RA. On the contrary, it seems that these exercises have a protective effect for the joints of the feet.

Because the underlying pathophysiological mechanism is not fully elucidated more research should be done on the effects of high intensity weightbearing exercises and cartilage metabolism.

\section{ACKNOWLEDGEMENTS}

We are very grateful to the patients for their trust and participation. We thank the assessors, I Perquin, B Oud, M Fluit, and M van Gulijk for performing the clinical assessments, Professor A Cats (AC) for reading the radiographs, and Dr and Mrs JD Macfarlane for critically reviewing the manuscript.

\section{Authors' affiliations}

Z de Jong, F C Breedveld, T P M Vliet Vlieland, J M W Hazes,

T W J Huizinga, Department of Rheumatology, Leiden University Medical Centre (LUMC), Leiden, The Netherlands

M Munneke, Department of Physical and Occupational Therapy, LUMC, Leiden, The Netherlands

A H Zwinderman, Department of Medical Statistics, LUMC, Leiden, The Netherlands

H M Kroon, Department of Radiology, LUMC, Leiden, The Netherlands K H Ronday, Leyenburg Hospital, The Hague, The Netherlands W F Lems, B A C Dijkmans, Department of Rheumatology, Vrije Universiteit Medical Centre, Amsterdam, The Netherlands

J M W Hazes, Department of Rheumatology, Erasmus University Medical Centre, Rotterdam, The Netherlands

\section{REFERENCES}

1 Laan RF, van Riel PL, van de Putte LB. Bone mass in patients with rheumatoid arthritis. Ann Rheum Dis 1992;51:826-32.

2 Haugeberg G, Uhlig T, Falch JA, Halse Jl, Kvien TK. Bone mineral density and frequency of osteoporosis in female patients with rheumatoid arthritis: results from 394 patients in the Oslo County Rheumatoid Arthritis register. Arthritis Rheum 2000:43:522-30.

3 Laan RF, Buijs WC, Verbeek AL, Draad MP, Corstens FH, van de Putte LB, et al. Bone mineral density in patients with recent onset rheumatoid arthritis: influence of disease activity and functional capacity. Ann Rheum Dis 1993;52:21-6.

4 Gough AK, Lilley J, Eyre S, Holder RL, Emery P. Generalised bone loss in patients with early rheumatoid arthritis [see comments]. Lancet 1994;344:23-7.

5 Saario R, Sonninen P, Mottonen T, Viikari J, Toivanen A. Bone mineral density of the lumbar spine in patients with advanced rheumatoid arthritis. Influence of functional capacity and corticosteroid use. Scand J Rheumatol 1999;28:363-7.

6 Lodder MC, Haugeberg G, Lems WF, Uhlig T, Orstavik RE, Kostense PJ, et al. Radiographic damage associated with low bone mineral density and vertebral deformities in rheumatoid arthritis: the Oslo-Truro-Amsterdam (OSTRA) collaborative study. Arthritis Rheum 2003;49:209-15.

7 Forsblad D'Élia H, Larsen A, Waltbrand E, Kvist G, Melstrom, Saxne T, et al. Radiographic joint destruction in postmenopausal rheumatoid arthritis is strongly associated with generalised osteoporosis. Ann Rheum Dis 2003;62:617-23.

8 Gough A, Sambrook P, Devlin J, Huissoon A, Nieh C, Robbins S, et al. Osteoclastic activation is the principal mechanism leading to secondary osteoporosis in rheumatoid arthritis. J Rheumatol 1998;25:1282-9.

9 Romas E, Gillespie MT, Martin TJ. Involvement of receptor activator of NFkappaB ligand and tumor necrosis factor-alpha in bone destruction in rheumatoid arthritis. Bone 2002;30:340-6.

10 Redlich K, Hayer S, Ricci R, David JP, Tohidast-Akrad M, Kollias G, et al. Osteoclasts are essential for TNF-alpha-mediated joint destruction. J Clin Invest 2002;110:1419-27.

11 de Jong Z, Munneke M, Zwinderman AH, Kroon HK, Jansen A, Ronday HK, et al. Is a long-term high-intensity exercise program effective and safe in patients with rheumatoid arthritis? Results of a randomized controlled trial. Arthritis Rheum 2003;48:2415-24.

12 de Jong Z, Munneke M, Lems WF, Zwinderman AH, Kroon HM, Pauwels EK, et al. Slowing of bone loss in patients with rheumatoid arthritis by long-term high-intensity exercise: results of a randomized, controlled trial. Arthritis Rheum 2004:50:1066-76.

13 Nordemar R, Ekblom B, Zachrisson L, Lundqvist K. Physical training in rheumatoid arthritis: a controlled long-term study. Scand J Rheumatol 1981;10:17-23.

14 Hansen TM, Hansen G, Langgaard AM, Rasmussen JO. Longterm physical training in rheumatoid arthritis. A randomized trial with different training programs and blinded observers. Scand J Rheumatol 1993;22:107-12.

15 Stenström CH, Lindell B, Swanberg E, Swanberg P, Harms-Ringdahl K, Nordemar R. Intensive dynamic training in water for rheumatoid arthritis functional class II-a long-term study of effects. Scand J Rheumatol 1991;20:358-65

16 Häkkinen A, Sokka T, Kotaniemi A, Hannonen P. A randomized two-year study of the effects of dynamic strength training on muscle strength, disease activity, functional capacity, and bone mineral density in early rheumatoid arthritis. Arthritis Rheum 2001;44:515-22.

17 Arnett FC, Edworthy SM, Bloch DA, McShane DJ, Fries JF, Cooper NS, et al. The American Rheumatism Association 1987 revised criteria for the classification of rheumatoid arthritis. Arthritis Rheum 1988;31:315-24.

18 Hochberg MC, Chang RW, Dwosh I, Lindsey S, Pincus T, Wolfe F. The American College of Rheumatology 1991 revised criteria for the classification of global functional status in rheumatoid arthritis. Arthritis Rheum 1992;35:498-502.

19 Larsen A, Dale K, Eek M. Radiographic evaluation of rheumatoid arthritis and related conditions by standard reference films. Acta Radiol Diagn 1977; 18:481-91.

20 Scott DL, Houssien DA, Laasonen L. Proposed modification to Larsen's scoring methods for hand and wrist radiographs. Br J Rheumatol 1995;34:56.

21 Scott D, van Riel PL, van der Heijde DM, Studnicka Benkem A. Assessing disease activity in rheumatoid arthritis. The EULAR handbook of standard methods 2002

22 Wallin L, Brudin LH. Physical working capacity determined by different types of bicycle exercise tests. Clin Physiol 1988;8:529-37.

23 van den Ende CHM, Hazes JMW, le Cessie S, Mulder WJ, Belfor DG Breedveld FC, et al. Comparison of high and low intensity training in well controlled rheumatoid arthritis: results of a randomised clinical trial. Ann Rheum Dis 1996;55:798-805.

24 Wells GA, Tugwell P, Kraag GR, Baker PR, Groh J, Redelmeier DA. Minimum important difference between patients with rheumatoid arthritis: the patient's perspective. J Rheumatol 1993;20:557-60.

25 Lassere M, Boers M, van der Heijde D, Boonen A, Edmonds J, Saudan A, et al. Smallest detectable difference in radiological progression. J Rheumatol 1999;26:731-9.

26 Heinonen A, Kannus P, Sievanen H, Oja P, Pasanen M, Rinne M, et al. Randomised controlled trial of effect of high-impact exercise on selected risk factors for osteoporotic fractures. Lancet 1996;348:1343-7.

27 Heinonen A, Sievanen H, Kannus P, Oja P, Vuori I. Site-specific skeletal response to long-term weight training seems to be atributable to principa loading modality: a pQCT study on female weightlifters. Calcif Tissue Int 2002;70:469-74

28 Pettit AR, Ji H, von Stechow D, Muller R, Goldring SR, Choi Y, et al. TRANCE/ RANKL knockout mice are protected from bone erosion in a serum transfer model of arthritis. Am J Pathol 2001;159:1689-99.

29 Goldring SR, Gravallese EM. Mechanisms of bone loss in inflammatory arthritis: diagnosis and therapeutic implications. Arthritis Res 2000;2:33-7.

30 Gravallese EM, Manning C, Tsay A, Naito A, Pan C, Amento E, et al. Synovial tissue in rheumatoid arthritis is a source of osteoclast differentiation factor. Arthritis Rheum 2000;43:250-8.

31 Khosla S. Minireview: the OPG/RANKL/RANK system. Endocrinology 2001;142:5050-5.

32 Jones DH, Kong YY, Penninger JM. Role of RANKL and RANK in bone loss and arthritis. Ann Rheum Dis 2002;61(suppl II):ii32-9.

33 Drossaers-Bakker KW, de Buck M, van Zeben D, Zwinderman $A H$, Breedveld FC, Hazes JMW. Long-term course and outcome of functional capacity in rheumatoid arthritis: the effect of disease activity and radiologic damage over time. Arthritis Rheum 1999;42:1854-60.

34 van der Heijde D, Simon L, Smolen J, Strand V, Sharp J, Boers M, et al. How to report radiographic data in randomized clinical trial in rheumatoid arthritis: guidelines from roundtable discussion. Arthritis Rheum 2002;47:215-18. 